Marketing in Asia Group

\title{
Does Organization Inclusion Matter in Expatriate Mission Accomplishment?
}

\author{
Hooi Lai Wan \\ College of Management, Chang Jung Christian University, Taiwan
}

\begin{abstract}
The main goal of the study is to explore if organisational inclusion features prominently in the expatriation policies of companies in emerging markets. In this study, the expatriation policies of three Taiwanese financial services institutions were examined to establish the presence or lack of organisational inclusion and its effect on expatriate mission accomplishment. In-depth interviews with the expatriates and faceto-face focus group discussions with senior HR managers at their headquarters in Taipei were employed to collect data from financial services institutions. The findings revealed that organisational inclusion is low, but the organizations are considering a more inclusive approach in future. Among the factors that emphasize the need for more organisational inclusion expatriation are cultural competence, social norms adjustment, positive mindset, professional skills and career-related factors. The study contributes to knowledge on how the financial services industry in emerging economies in the Chinese context view organisational inclusion in their expatriation policies. It further provides an insight of the necessity to embrace organisational inclusion in the expatriation policies to enhance expatriate mission accomplishment.
\end{abstract}

Keywords: Organisational Inclusion, Emerging Markets, Taiwan, Mission Accomplishment, Expatriates, Financial Services Industry

Publication Details: Received 19 June 2020; Revised 5 Oct 2020; Accepted 30 Oct 2020 


\section{Introduction}

The liberalization of cross-border markets, the digital revolution and a dynamic increase in corporate globalization require organizations to reconsider how to boost the performance of their global employees. Research on global mobility shows a number of determinants that are critical for expatriate mission accomplishment. Caligiuri and Bonache (2016) emphasize on a new managerial mindset in the current era of globalization - one that is labelled as geocentrism, global mindset or transnational mentality. The geocentric approach in expatriation focuses on deploying the best people regardless of nationality to any country within the organization. Global managers need to adopt a geocentric perspective and recognize that the best people are not linked to any nationality. While this is an ideal global decision-making system, the headquarter-cantered ethnocentric perspective prevails in the early years of the globalization era, and perhaps continues to dominate in the near future (Caligiuri and Bonache, 2016). Greater globalization and a more competitive business reality require business professionals to recognize what is distinctive to a particular culture and what is universal within the contingencies of the local environment (Levy et al., 2007). Moreover, global managers need to understand the complexity associated with globalization and be able to respond strategically to sustain competitiveness. However, existing literature focus on issues relating to expatriates' role, performance, adjustment, success, and failure with minimal scholarly attention given to the decision-making criteria in the selection of expatriates (Ott and Michailova, 2016).

Anchored in Nicholson's (1984) work role transition theory and Nijs et al. (2014) ability-affective talent framework, this study aims to examine if organisational inclusion matters in expatriate mission accomplishment through an analysis of the financial services industry in Taiwan. As organizations expand their global reach, accomplishing corporate missions abroad, broadly defined as the successful completion of expatriation and adequate performance in fulfilling corporate international endeavours and responsibilities (Hooi, 2019), is central for competitiveness. Indubitably, emerging economies such as Taiwan has benefited from globalization and regional economic development, yet they are vulnerable to global economic downturn and trade frictions (Taiwan News, 2019). Despite emerging tops among the "Four Asian Tigers", the success or failure of corporate missions abroad depends to a considerable extent on the performance of their expatriates. Undeniably, for emerging economies such as Taiwan, globally mobile and agile employees have grown in importance (Caligiuri and Bonache, 2016).

Therefore, deployment of the right people are crucial for accomplishing missions abroad (Cheng and Lin, 2009). Essentially, organizations have to select not only talents that possess innate abilities and systematically develop them, but also have to match the motivation and interest of the potential assignees. Nijs et al. (2014) assert that both the ability (innate ability and systematic development) and affective component (motivation to invest energy and interest areas) of talents provide a better prediction of interpersonal and intrapersonal excellence. Likewise, Nicholson (1984) argues that work role transitions potentially affect the individual profoundly, as the level of personal and organisational adjustment depends largely on the characteristics of the individuals. Role requirements, motivational orientations, prior occupational socialization and the induction-socialization process indubitably influence individual 
adjustment, which in turn determines individual performance. Essentially, in the context of expatriation, the ability of expatriates to enhance technical skills, selfmotivate and culturally adjust matter in accomplishing missions abroad.

A review of present literature on expatriation research in the last five years reveals limited studies examining organisational inclusion as a determinant of expatriation success. Most studies affirm that organisational inclusion produce positive workplace outcomes in both for-profit and non-profit organizations. Brimhall's (2019) study, for instance, asserts that in non-profit organizations, organisational inclusion leads to increased innovation, employee job satisfaction, and perceived quality of care while Qi et al. (2019) affirm that inclusive leadership significantly affects perceived organisational support and employee innovative behaviour. Davies et al.'s (2019) study contends that organisational inclusion moderates the relationship between expatriate resilience and work adjustment, and turnover intentions through work adjustment. Perceived organisational inclusion in the study focused on the receptiveness and support of host country nationals to facilitate expatriates become integrated members of the organization. As studies show that host country nationals are more likely to offer support to expatriates who are more culturally similar to them (e.g., Varma et al., 2012; Pichler et al., 2012), the selection of expatriates that are culturally similar to host country nationals potentially promotes expatriate mission accomplishment. Hence, the focus is on developing potential expatriates across generations and cultures inclusively and providing them with equal access to opportunities to contribute fully to the accomplishment of corporate missions abroad. As Taiwan is highly culturally homogeneous (Zhong, 2016), the inevitable friction between Taiwanese expatriates and culturally dissimilar host country nationals may jeopardize expatriate mission accomplishment.

This study aims to provide a sound underpinning for the field of expatriation by revealing the presence or absence of organisational inclusion in the expatriation policies. Drawing from Ainscow et al.'s (2006) definition of inclusive education, organisational inclusion for this study involves the identification and removal of hindrances to the presence, participation and achievement of all expatriates. Specifically, it attempts to establish if organisational inclusion potentially enhances expatriate mission accomplishments of companies in emerging markets, especially in the Chinese context. This study is notable to support existing scholarship on global mobility, emphasizing on an inclusive approach to the identification of the right people for expatriation. For organizations to leverage globalization to enhance competitive advantage, it is crucial that potential expatriates possess the $3 \mathrm{Cs}$, namely, the capability, commitment and chemistry to excel in their expatriate assignments. The likelihood of identifying these people is much enhanced if organisational inclusion is considered in expatriate identification policies. 


\section{Theoretical Background}

\section{Organisational Inclusion in Expatriation}

Organisational inclusion, as defined by The Society of Human Resource Management, refers to "the achievement of a work environment in which all individuals are treated fairly and respectfully, have equal access to opportunities and resources, and can contribute fully to the organization's success" (Talent Intelligence, 2014). Therefore, an inclusive culture where everyone feels valued and respected (Brimhall, 2019; Global Diversity Practice, 2017; Wallace and Pillans, 2016) and is able to wholly contribute is imperative. When everyone regardless of generation and culture can fully participate in the workplace and has equal access to opportunities (Thompson, 2017), people feel empowered to contribute their skills and perspectives for the benefit of organisational performance and business outcomes. Hence, organizations ought to discover ways to develop potential expatriates across generations and cultures inclusively. An inclusive climate among others enhances employee commitment (Cho and Mor Barak, 2008; Hwang and Hopkins, 2012); retention (Buttner, Lowe, and Billings-Harris, 2012; Hwang and Hopkins, 2012) and improved self-esteem (Vakalahi, 2012), all of which are associated with favourable attitudes that are vital for performance (Mitchell et al., 2015). In efforts to enhance mission accomplishment abroad, it is critical that organizations create a culture of inclusion where multigenerational and multicultural dynamics can thrive.

While the key expatriate issues are today as they were decades, if not centuries ago, the context has changed dramatically (Caligiuri and Bonache, 2016). Dramatic changes can be observed in the strategic deployment of expatriates (Bucker et al., 2020), changes in assignment types (Liisa, Saarenpää and McNulty, 2017), and demographic changes in the profile of expatriates (Baruch et al., 2016). For instance, expatriates are no longer restricted to married male senior executives from headquarters to control or to fill a managerial skills gap in overseas subsidiaries. Moreover, there is a rising trend of self-initiated expatriates that are entering the organization at all levels (Selmer et al., 2015; Tharenou, 2013). Global mobility will continue to diversify and a human centric global mobility experience that engages the individual is essential to attract, motivate, and develop global human resources (Deloitte, 2019).

Besides, the rise of digitalization fosters consumer-oriented models of HR-related service delivery, which among others, encourage flexible management of employee relocations and personal choice for repositioning in global destinations. Deloitte (2019) further affirms that global mobility's scope is diversifying with activities such as international recruitment, global workforce planning and location strategy gaining traction. Future mobility that entails shorter duration assignments and more flexible approaches (Deloitte, 2019; KPMG, 2019), such as extended business trips, shortterm assignments, commuter models, immersive experiences, (Liisa, Saarenpää and McNulty, 2017) and developmental/training assignments further fosters mobility opportunities to a more inclusive employee population as well as support talent development. Moreover, as international experience is pivotal for future leader development (Crown World Mobility, 2019) and the fundamental trend in organisational thinking is the shift towards enhancing employee experience (BGRS, 2019), inclusion and reducing barriers to global mobility is essential. 
Additionally, in view of globalization, digitalization, advances in communication and global mobility, organizations are beginning to feel the impact of demographic changes in their employee base. As the newest generation of workers, the Centennials, blazes in, coupled with a booming global workforce, today's workplace dynamics demand a culture of inclusion. Organizations, therefore, have to accommodate this change in order to optimally utilize talents to achieve growth. The Millennials, for instance, prefer to be associated with organizations where inclusion is a priority while the Centennials expect the workplace to conform to their wishes (Patel, 2017) as well as provide career advancement opportunities (Half, 2018). Moreover, recent studies (e.g., Deloitte, 2019) have shown an inclination towards a more purposeful approach to global mobility, that is, integrating talent management with global mobility (Collings, 2014) throughout the employment life cycle.

As global assignments form a formal part of the talent management process, an inclusive approach would provide organizations a global talent pool of potential expatriates to create a dynamic future-proofed workforce that fosters mission accomplishment. Generally speaking, global organizations ought to leverage the internal pool of talents as well as attract new talents. A mobile workforce is an enabler of business and talent strategies (Deloitte, 2019), and organisational inclusion provides opportunities to increase the pool of mobile workforce. Moreover, as organizations contemplate the digitalization of the global mobility function and believe that new communication tools improve personal productivity (Deloitte, 2019), it is imperative to include the digital natives in expatriate selection. Further, with LGBT progress and the legalization of same-sex marriage in Taiwan in May 2019, Taiwan global organizations may need to consider the LGBT community as well. Besides, Taiwan encourages the meaningful inclusion of disabled people in the workforce. To avoid anti-discrimination laws (Chen, 2019) and monetary fines (Jang et al., 2014), people with disabilities ought to be given equal consideration. However, a study by $\mathrm{Hu}$ et al. (2010) revealed 15 key criteria that Taiwanese enterprises used to select candidates for expatriation. The criteria in these enterprises include integrity, loyalty, tenacity, crisis management, decision-making ability, execution, independence, professional skills and knowledge required for the foreign assignment, working performance, willingness, self-confidence, resilience, ambition, and prior work experience, which indicated limited inclusion in terms of new, young talents.

\section{The Taiwan Context}

Taiwan's outward investment began in the 1950s, but since the 1960s, Taiwanese companies have invested significantly abroad (Hsiao and Hsiao, n.d.). Taiwan outward foreign direct investment has increased dramatically since 1987 partly due to the relaxation of foreign exchange regulation by the Taiwanese government and the escalating domestic labour costs. Moreover, the support of the Taiwanese government in various initiatives such as the Industry-Oriented Human Capital Training Programs, Overseas Taiwanese Business Management Improvement Project, Talent Matching for Taiwanese Businesses Aiming at ASEAN Markets and Overseas Investment Loans and Export Financing Program under the New Southbound Policy, enables organizations to leverage these policies to expand businesses offshore in the 18 partner countries. As of June 2016, there are 189 subsidiaries of Taiwanese banks or financial institutes in ASEAN, South Asian countries and Australia. Hence, Taiwanese investment continues to grow at an increasing rate in the new millennium, 
primarily into emerging markets (Hooi, 2019). Indubitably, this is a positive business trend, but the current era of globalization (Shiraki, 2015) and digital transformation have increased the complexity of corporate globalization. For Taiwanese companies to leverage globalization and digitalization to enhance competitive advantage, it is imperative that Taiwanese global corporations have the right expatriates to foster mission accomplishment abroad.

As motivation plays a central role in achieving excellence due to its positive influence on willingness, capacity and preference to engage in deliberate practices, defined as activities that are structured to achieve organisational goals (Nijs et al., 2014), the deployment of motivated people to an environment that matches their interest potentially increases the likelihood of mission accomplishment. The deployment of expatriates based solely on ability may be insufficient for mission accomplishment abroad. Specifically, in the case of Taiwan, the comforts of the home environment, forgone opportunities during expatriation, and the fear of working in an unfamiliar setting, deter employees from expatriating (Hooi, 2019). The primary motive for most Taiwanese to accept expatriation is for career development (Ko, 2008), but it is unclear whether, when or how these expected career progressions are met (Dowling and Welch, 2005).

Hence, considering the difficulty of enticing Taiwanese to expatriate, particularly to less developed countries, organizations in Taiwan may have to employ a more inclusive approach in the identification of people for expatriation, which means systematically developing innate abilities of those individuals who expressed an interest to be expatriated, and not select based on technical abilities. Moreover, it is easier for expatriates to adjust if they were transitioned to a role they are interested and are motivated to invest energy for optimal performance of the new role. Nicholson's (1984) work role transition theory that links personal and organisational adjustment outcomes with the characteristics of the person, the role, and the organization, contends that individuals have to either alter their new roles to better match their characteristics or alter their own attitudes and behaviours to better fit their new roles. In essence, organisational inclusion, where all individuals are treated fairly and respectfully, and have equal access to opportunities and resources (Talent Intelligence, 2014) provides organizations with a wider pool of candidates to be considered for expatriation, and enhances the likelihood of identifying the right candidates that could transition with less difficulty. Hence, considering organisational inclusion in expatriation may be vital in the context of Taiwanese global corporations.

\section{Methodological Approach and Research Design}

The study was based on in-depth accounts of eight senior human resource managers and 28 Taiwanese expatriates. Permission was obtained from three major financial services institutions in Taipei to participate in the study. The Vice President or Senior HR Manager of the financial services institutions recommended eight senior HR managers from the headquarters to participate in the focus group discussions - three each from two financial services institutions and two from the other organization. They are equally represented in terms of gender and four are in their early careers (ages 24-35), three in mid-career (ages 36-45), and one in late career (ages 46-60) (O'Neil and Bilimoria, 2005). Half of the participants has more than 10 years of 
working experience and has between six to more than 15 years of expatriate experience after serving the organization for between six to 10 years before expatriation. Three are married and all participants are qualified to graduate level. These participants are experienced and are directly involved in managing international assignments.

To capture the individual perspective, 28 Taiwanese expatriates based in various foreign subsidiaries in the region were interviewed. As there were no further new emerging themes, the Human Resource Departments were advised that it was not necessary to identify more participants to be interviewed. All but six of the participants are qualified to the graduate level. Fifteen of the participants are in their early careers, seven in mid-career and six in late career. The majority of the participants has more than five years of working experience $(92.8 \%)$, between three to five years of expatriate experience $(35.7 \%)$ and at least three years of service with the company before expatriation $(82.1 \%)$. Half of the participants are married.

Data was collected through focus group discussions and in-depth individual online interviews. Prior permission was obtained from top management of each financial institution before conducting the study. A description of the purpose and benefits of the study were discussed with the participants before the session. Efforts were made to ensure confidentiality and that the research participants did not suffer discomfort, embarrassment or loss of privacy. The participants gave their informed consent before participating in the research. The content validity of the questions developed for the focus group discussion and interviews was verified through critical feedback from two academicians and three practitioners. Based on their feedback on the nature of the questions, changes were made to enhance the relevancy and comprehensibility of the questions. The questions were designed to capture the senior HR managers' and the Taiwanese expatriates' perspectives of their organization's expatriation policies, specifically their perspectives on organisational inclusion based on the work role transition theory and the ability-affective talent framework. Probing questions were used to elicit in-depth information. Data collection and analysis were carried out discretely (Silverman, 2018).

The qualitative data were generated in two distinctive stages. The first stage involved a focus group discussion with the senior HR managers, which was conducted face-toface using the refined semi-structured questions. The aim of the focus group discussion was to gain insight into the participants' collective memory (Patton, 2015) and for the author to have a profound understanding of key issues from different perspectives within the organization. The author who had vast experience of interviewing in varied research contexts led the discussion in a private room. Efforts were made to establish rapport with the participants before diving into the core of the discussion. Extra attention was paid to body language while probing for details. Verifications were sought throughout the discussion and no assumptions made. With permission of the participants, digital recording of the discussion was made. The recordings were later transcribed verbatim into written form and sent back to the participants for verification of the contents captured. Using a 'bottom up' approach (Shepherd and Sutcliffe, 2011), the notes and transcripts were analysed and a summary of the discussion was drafted. 
The in-depth individual online interviews (Brinkmann and Kvale, 2015) lasted between an hour and an hour-and-a-half. These involved 28 expatriates identified by the HR departments and were based in various foreign subsidiaries in the region. Themes identified from the focus group discussion were used as a starting point for the interviews. Data collected from the expatriates were similarly transcribed and verification was done using online platforms. Verification and feedback from the participants were necessary to ensure accurate interpretation of the data (Bansal and Corley, 2011) and for establishing credibility (Guba and Lincoln, 1989). In addition to the interviews, email exchanges were initiated with the participants throughout the period of data analysis to collect developing thoughts. This iterative, reflexive dimension was incorporated in the analysis. Every effort was made to adhere to the naturalistic paradigm to interpret the underlying context. Reading the transcripts and written notes provides a sense of the whole. Finally, all participants were invited to comment on the paper, which was sent to them. As per ethical guidelines, all research-related undertakings such as digital recordings, transcripts, permissions and notes were exhaustively documented.

The analysis of the data first involved descriptive, open coding techniques, and then axial coding to develop second-order themes (Silverman, 2018). The first-order analysis used informant-centric codes (Gioia et al., 2012) while the second-order analysis concentrated on researcher-centric codes. Second-order themes were developed from the first-order themes and concepts from the literature review (Van Manaan, 1979). Using Hammersley and Atkinson's (1995) notion of “progressive focusing", dominant themes were sub-categorized while less dominant themes were merged. The objective was to ensure that contrasting and minority views of the participants were incorporated in the analysis. Data were revisited throughout the process to draw inferences on the basis of codes and categories generated. From these patterns, key themes evolved and illustrative quotes from each transcript were determined. The final stage of the data analysis involved categorizing the codes into two central themes, namely, organisational inclusion in expatriation policies and embracing organisational inclusion. As the interpretation of the data might have been influenced by the understandings of extant literature (Weick, 1995), the analytic process was not purely inductive.

\section{Findings}

\section{Organisational Inclusion in Expatriation Policies}

This section presents the findings from the study illustrated by excerpts from participants' narratives with regards to expatriation policies. As far as organizational inclusion pertaining to expatriation is concerned, while limited to a certain extent, it is definitely more so now as compared to before. Traditionally, these companies expatriate only senior staff to foreign subsidiaries. However, due to the reluctance of senior management staff to be based abroad, particularly in less developed countries, the companies have been considering younger staff for expatriation. Unmarried young Taiwanese males with international exposure and English proficiency are preferred mainly due to safety concerns though for some safer countries such as Singapore, females are also considered. 
[...] depends on the safety environment [...] we want to expatriate males in South East Asia, but in some countries like Singapore or Hong Kong [...] is quite safe compared to South East Asia, so females are also expatriated [...] (HR2)

However, only new recruits with at least three years of service in the company in Taiwan will be considered for expatriation. New recruits, Taiwanese or otherwise, have limited opportunity to be expatriated. Due to the increasing demand for certain expertise, foreign nationals were hired and trained in Taiwan before expatriating them. Under the Overseas Business Associate Plan, one of the companies recruits overseas Chinese students from Hong Kong, China and Macau, and other outstanding international students, trains them in Taiwan, and then expatriates them to the subsidiaries in their home countries. Additionally, the company trains Taiwanese management trainees for 'second generation expatriation' under the Plan. Freshmen that have potential and are willing to be expatriated are trained under the Management Associate Program.

In each subsidiary, between five to seven Taiwanese expatriates are sent mainly to service Taiwanese corporate clients in the host countries. However, compliance matters are left to the local professionals while the Taiwanese expatriates focused on risk management in the overseas subsidiary. As the expatriation term for managers is five years and operation staff three years, with the option to extend for another term, and then to localize on expiration of the two terms, there is little urgency to consider new recruits for expatriation. While this is a hindrance to organizational inclusion, the 'no forced expatriation' policy renders this necessary, as employees that are unwilling to be expatriated can remain in Taiwan with no repercussions on their career. Filial piety and fulfilling family obligations are part and parcel of Taiwanese culture and organizations do respect the wishes of employees in this aspect. Additionally, there is practically no training to prepare expatriates for repatriation and the limited access to resources before being repatriated further heightens the anxiety of potential expatriates. Besides, there are minimal development opportunities during expatriation and some who decide to remain in Taiwan have progressed in their career at a much faster rate. This deters some from accepting expatriation though expatriates are not overly concerned as the company adopts a 'no demotion' policy.

[...] definitely not demotion, but not everyone will get promotion [...] expatriate they will get higher chance to get promotion [...] (HR1)

\section{Embracing Organisational Inclusion}

Despite limited emphasis on organizational inclusion thus far, the participating companies recognized a number of factors that justified the need for more inclusion in their expatriation policies to enhance mission accomplishment. These include cultural competence, social norms adjustment, positive mindset, professional skills and careerrelated factors. 


\section{Cultural Competence}

The difficulty of assimilating in the host country to some extent affected expatriate performance. The discontentment raised by the expatriates mainly concerned cultural differences. As there is limited emphasis on cross-cultural training before expatriation and practically none during expatriation, senior management recognized that people with high cultural intelligence might buffer the impact. Though currently priority is given to senior staff, the companies emphasize the need to refocus the criteria to seriously consider candidates that display high cultural intelligence, regardless of seniority. The national culture of Taiwan is anticipated to be similar to China, Hong Kong or Singapore, but the cultural context differs from one country to another. Based on Hofstede's cultural dimensions, these countries shared almost similar values in terms of individualism (low), masculinity (medium) and long-term orientation (high). But in reality, cultural differences do exist in a way that the Taiwanese expatriates find it difficult to express.

[...] cultural shock or political issue in Hong Kong or China [...] we are Taiwanese $[\ldots]$ have some issues $[\ldots]($ Exp20)

$[\ldots]$ the China people do not go very well with the Taiwan people [...] (Exp 11)

Moreover, contrary to preconceived notions of the similarities, Taiwanese expatriates, for instance, perceived themselves as more hardworking compared to their Chinese counterparts. The Chinese employees adhere strictly to the terms in their contracts and leave the office once official hours are over. Tensions inevitably exist and to ease the situation, Taiwanese expatriates must tactfully deal with local agitation and adopt appropriate coping strategies (Cheng and Lin, 2009). Indubitably, expatriates that have difficulty adjusting to the different work ethics and culture in the foreign subsidiary indicated unpleasant experience during expatriation, which affected their work.

[...] in Taiwan work overtime is quite common, but for the Chinese they don't think so [...] if 5.30 is the end of the day's work, they will just stand up and leave $[\ldots]$ I just follow the company's regulation [...] (Exp11)

\section{Social Norms Adjustment}

Taiwanese expatriates acknowledged the need to adjust to the local social norms to enhance professional and personal integration as well as mitigate the formation of subgroups or cliques within the organization. Moreover, they faced less frustration if they were able to work harmoniously alongside their local counterparts. Those that recognized cultural diversity were able to manage their cross-cultural adjustment and have lesser tendency to interact only with Taiwanese staff and act the Taiwanese way in the companies. These expatriates could assimilate well with the local community, which added to the overall affirmative experience during expatriation. Unfortunately, there is a tendency for the Taiwanese expatriates to mix with and protect their own countrymen in the organization. 
[...] if you are Taiwan people you may want to protect your Taiwan people more and for the local people you may want to protect the local people more [...] (HR6)

\section{Positive Mindset}

Positivity of Taiwanese expatriates, particularly, open-mindedness to accept cultural differences, is equally important. Other positive traits identified by the expatriates include being honest, independent, diligent, creative, proactive, efficient, responsible, resilient, intelligent, quick, professional, cooperative, humble, positive, warm-hearted, easy going, active, adventurous, outgoing, flexible, ambitious and adaptable. To capture these positive traits, the companies are considering a more open approach to reach a wider spectrum of candidates in their future expatriation policies. Expatriates that can be in Singapore today and Cambodia next, adjust better. Among all factors, cultural adaptability features prominently, indicating that expatriates have to be prepared for the differences that they may encounter in the new working environment to enhance mission accomplishment.

$[\ldots]$ we have to tell them when you go to a foreign country you have to work different $[\ldots]$ you have to change the mindset $[\ldots]$ the mindset is very important $[\ldots]$ (HR2)

\section{Professional Skills}

Some of the essential professional skills identified by the expatriates that matter in expatriate mission accomplishment include communication skills, leadership skills, entrepreneurial skills, critical thinking skills, high emotional intelligence, social skills and networking skills. Among these, good communication skills, particularly, the ability to speak English well, appear to be the most important. Being multilingual and experience working in different countries are plus points. Candidates with the right professional skills are identified and placed in the talent pool for further development. This creates a pipeline of talents that are ready for expatriation. Though the intensity varies from one company to another, every company makes an effort to identify global talents. Currently, the focus is on young, flexible Taiwanese with international exposure and linguistic skills, particularly, English. The companies acknowledged that English competency and international exposure are "must have" rather than "good to have".

Most of us in Taiwan are more focused on English and overseas education background. (HR5)

To portray a more global image and to tap on foreign expertise, some of the companies have also started recruiting foreign nationals.

$[\ldots]$ we will have more talents if we hire foreign talents [...] (HR7)

\section{Career-Related Factors}

The companies are also inclining towards a more inclusive approach due to career and work-related factors. Younger, unmarried employees are more willing to forgo the comforts of home in anticipation of a brighter future in the later part of their career. 
Taken positively, expatriation is seen as an opportunity for personal development. Besides, the compensation package may be motivating for some, particularly, younger expatriates to perform their utmost for the organization.

Offering an ideal expatriation deal and benefits are the best ways to achieve sustainable business. (HR7)

Additionally, some companies make expatriation experience a criterion for promotion while others expedite the promotion of repatriates that have performed well during expatriation. As such, staff that are not tied down by family commitments or limited by other constraints are willing to be expatriated specially to developed nations or to places where quality of life is high. In this, the companies support their expatriates in every way possible, as they believed that a relaxed working environment could also enhance expatriate mission accomplishment. The Taiwanese expatriates favour a balance lifestyle while abroad, probably because they come from affluent families.

Young Taiwanese want work-life balance [...] probably their parents are rich [...] (HR3)

Likewise, the younger locals considered work-life balance an important part of their lifestyle. Therefore, Taiwanese expatriates that can adjust to this welcome the shorter working hour. In Hong Kong, for instance, an official working day is 7.5 hours, whilst in Taiwan it is eight hours. But, in Taiwan, working 10 hours daily is the norm in the headquarters and local subsidiaries.

Most of the locals that join our bank are more relaxed because working hours are controllable [...] they don't want to work overtime [...] they can have the work-life balance [...] (HR5)

Simultaneously, some Taiwanese expatriates lamented that some local Chinese are not willing to work overtime, a practice common in Taiwan. Under the 'Responsibility System' in Taiwanese corporations, it is the responsibility of employees to complete the assigned tasks. Hence, it is not unusual for Taiwanese expatriates to work beyond office hours. Similarly, Taiwanese expatriates in Hong Kong and Singapore observed differences in work cultures that frustrate them. For instance, Taiwanese expatriates will oblige requests from higher management, but not the locals. Moreover, the locals will not hesitate to leave for a better offer even though the difference in remuneration is negligible. Taiwanese expatriates just find this appalling and unacceptable.

Sometimes in Taiwan I tell the employees, please do this, I will give you bonus year end [...] Taiwan we will work hard, but in Hong Kong no way [...] you give me bonus first, I don't want to do this [...] In Singapore, I think it is the same and their loyalty is not quite strong [...] compare to Hong Kong, Singapore is better, in Hong Kong they leave for an extra of just 1000 HK dollar. (HR3) 


\section{Discussion}

The key themes identified in the discussion with the senior HR managers and expatriates induce the need for a more inclusive approach in expatriation. The participants do recognize that cultural competence, social norms adjustment, positive mindset, professional skills and career-related factors are crucial for mission accomplishment. As studies have proven the positive outcomes of organizational inclusion (e.g. Davies et. al., 2019; Liggans et al., 2019; Mohamed and Vesa, 2019), the organizations ought to foster organizational inclusion in the expatriation policies. However, organizational inclusion per se is unlikely to enhance expatriate mission accomplishment. Various issues need to be addressed and organizational support is vital.

Considering the reluctance of some Taiwanese to be expatriated, leveraging new young recruits through systematic development and motivating them to invest energy in bettering themselves may be an option worth considering. Nonetheless, the focus should not only be on unmarried individuals, but also, expatriates with families. Regardless of whether the families relocate with the expatriate or not, adequate training has to be given to both the expatriates and their families. As some Taiwanese expatriates leave their spouses and families in Taiwan (Cheng and Lin, 2009), family issues inevitably arise that may affect expatriates' performance. Hence, financial support for regular home visits and helping expatriates' family members left behind in Taiwan adjust to life without the expatriate may be necessary.

As the number of expatriates will increase further (FIDI, 2016), the 'no forced expatriation' policy means that it may be essential to enhance organizational inclusion in expatriation. The experience of senior employees may be critical for mission accomplishments, but favouring new recruits with international exposure and training foreign recruits in Taiwan before expatriating them to their homeland are perhaps wise moves. However, positive perceptions of expatriation and a clear repatriation policy are crucial. Scholars (e.g., Tung, 1987; Sharma and Dahiya, 2017) concur that expatriates' pleasant experiences likely promote successful expatriation. Though both individuals and organizations have a role in determining the experience felt, the emphasis is on supportive organizational policies (van der Laken et al., 2016).

First and foremost, organizations have to ensure that the expatriates have the capability to accomplish those missions. In this, organizations have to provide adequate training, which ideally should comprise of pre-departure training, during assignment training and re-entry training. Pre-departure training enhances crosscultural adjustment (Caligiuri et al. (2001) as it prepares expatriates with a new global managerial mindset (Caligiuri and Bonache, 2016). Likewise, Bhaskar-Shrinivas et al. (2005) affirm cross-cultural adjustment as a pertinent factor in openness to host cultures. As most of the expatriates echo the importance of cross-cultural adjustment and a global mindset for mission accomplishment, a primary concern is to enhance expatriate cultural awareness in order to assimilate quickly to the host country.

Expatriates should not feel "abandon" in a "lost planet" as this would affect their performance. Culture shock is inevitable even in host countries that have similar cultures as the parent companies. These dissimilarities promote undesirable work attitudes (Renn et al., 2013) and trigger intergroup tension (Pelled, 1996). It is crucial 
that headquarters provide support in bridging the divide otherwise it will affect organizational socialization, and ultimately, mission accomplishment. Organizational socialization is a challenge (Shah and Barker, 2017), as the expatriates and local employees develop their own inner circles among their countrymen. Based on the principle of homophily (Tung, 2016), people, in general, prefer those who are similar to them. Being able to socialize well helps expatriates assimilate better (BhaskarShrinivas et al., 2005; Searle and Ward, 1990) and promotes collaboration (Caligiuri, 2000) with host country nationals. Perhaps, it is best to select "persons whose cultural background is maximally similar to that of the new host culture" (Smith and Bond, 1993, p. 205), and that means more inclusion in the selection process.

To mitigate these problems, the companies may adopt more contemporary workplace designs where the layout itself provides a sense of work-life balance. A conducive, relaxed working environment with a family/collegiate atmosphere likely encourages more employee interaction while maintaining serenity at work. As "multicultural teams are here to stay" (Tung, 2016, p. 145), team building events are inevitable to promote organizational socialization. Mockaitis et al. (2018) further assert that global teams can act as a cross-cultural training tool, assist in developing global competence and provide leadership development. They further emphasize the vital role of human resource departments in "understanding, managing and leveraging the benefits of global teams to ensure that they contribute positively to the performance of firms, organizational units, and people" (p. 2137).

Moreover, as employees are connected 24/7, and probably working 24/7, the need for overtime should be reconsidered. As the younger generation values work-life balance, providing flexitime for employees to work from home is another option. As long as they abide by the 'Responsibility System', it does not matter much if employees were at the workplace for the duration of their working hours. What is important is, expatriates to be emotionally stable, as emotionally stable expatriates are likely to have better coping capabilities to tackle cultural ambiguity (Mendenhall and Oddou, 1985).

Emphasis should be given to re-entry training programs as expatriates experienced "culture shock back" upon repatriation. Uncertainty upon repatriation further discourages acceptance of expatriation. The findings reveal that expatriation does not seem enticing, as there is warranted evidence of faster career progression for those not expatriated. Why would they leave the comforts of their home, their family, and face loneliness in a land of uncertainty? Therefore, a repatriation policy that clearly defines the new assignment and re-entry position of the repatriate has to be in place. In essence, post-assignment guarantee is essential to entice expatriation. Organizational reconnection may be necessary to mitigate loss of visibility and isolation, especially for those who have been away for a long period of time. The companies should also provide assistance for non-work factors such as relocation and family adjustment. Preferably, a repatriation program should provide opportunities for repatriates to share their experiences rather than devalue them. This not only promotes knowledge transfer in terms of cross-cultural adjustment, personality traits, socialization and professional skills, but also, enhances employee willingness and readiness for expatriation. 


\section{Implications, Limitations and Suggestions for Future Research}

The theoretical contribution of this study is two-fold. First, this study contributes to organizational inclusion literature by providing a different perspective of organizational inclusion in expatriation. The current study emphasizes on inclusivity in the identification and selection of expatriates based on the Nijs et al. (2014) abilityaffective talent framework, unlike other studies that focused on inclusivity in the host country (e.g., Davies et al., 2019). The emphasis is on recognizing the innate ability of individuals and developing them systematically as well as encouraging them to invest effort to advance their competences. Further, it reveals the underlying reasons for the lack of organizational inclusion in the Chinese context, particularly in emerging economies.

Second, this study extends the expatriation literature by indicating that organizational inclusion in expatriation potentially fosters mission accomplishment of emerging economies in the Chinese context. While earlier studies (e.g., Cheng and Lin, 2009; Davies et al., 2019; Harari et al., 2018; Lauring et al., 2019; van de Laken et al., 2019) espouse on universal factors for expatriation success, this study highlights that both home country culture (e.g., filial piety) and characteristics (e.g., health care facilities, transport system, living conditions) may be significant influences that warrant consideration for a more inclusive approach to expatriation. Further, it suggests that cultural competence, social norms adjustment, positive mindset, professional skills and career-related factors are important factors that justify organizational inclusion in expatriation.

Likewise, this study contributes two perspectives on managerial implications. First, this study provides practitioners an insight of factors that could be considered in the identification and selection of expatriates. It suggests that an inclusive approach in tandem with the ability and affective components of talent will promote the identification of culturally fit expatriates that potentially enhance mission accomplishment abroad. This is in line with Davies et al. (2019) assertion that expatriate success is higher when expatriates perceive higher inclusion climate in the organization. Second, it provides a deeper understanding of the underlying reasons for more organizational inclusion in expatriation to foster mission accomplishment in emerging economies of Chinese context. This enlightens practitioners on measures that promote expatriation, particularly in the context of good home country conditions and high reluctance to be expatriated. Further, it provides some insights of the frictions that may arise when the political relationship between two countries is unfavourable.

This study's results should be interpreted in light of several limitations. The relatively small sample size suggests that generalizations should be made cautiously. Data collection was limited to focus group discussions with eight HR personnel in the headquarters and online interviews with 28 expatriates of three major financial services institutions in Taiwan. Time and resource constraints hinder more extensive data collection. Moreover, the current study is a snapshot in time, which makes it difficult to gain a more holistic view of the expatriates' experiences that may evolve and change over time. Hence, future research may undertake a longitudinal study to define the exact mechanisms that promote expatriate mission accomplishment. The scope of future studies could be extended to cover measures that organizations and 
expatriates take to overcome the challenges encountered during expatriation. Allocating more time and gaining access to more resources would provide a more profound understanding of how organizations select, develop, and retain expatriates to accomplish corporate missions abroad.

Another limitation is the use of a case study approach. It is argued that the case study method is particularistic and contextual, and may not be representative of a wider social setting to provide recommendations to other similar social settings (Starman, 2013; Welch and Piekkari, 2017). Furthermore, the findings of this study aggregated the data collected from the three financial services institutions with subsidiaries in various countries. Thus, the results may not represent the actual determinants in a certain country. Future studies may include more financial services institutions that have subsidiaries in different countries to understand how results differ in terms of country context. Future research focusing on each country separately to uncover the exact determinants pertinent to that country can offer an insight to steer the readiness of both organizations and potential expatriates to successfully accomplish corporate missions abroad.

\section{Conclusion}

The primary objective of this paper is to see the presence or lack of organizational inclusion and the factors that justify the need to embrace organizational inclusion in expatriation policies to foster mission accomplishment. The findings contribute to the understanding of determinants of successful expatriation. This helps organizations to select the right people and prepare them for expatriation to ensure successful businesses abroad. Details of the findings are summarized in each of the sections above. While some expatriate issues have been impervious to change over time, expatriate diversity is certain, and the context of Taiwan is no exception.

\section{Practical Implications for Asian Business}

The strategic deployment of expatriates is vital for mission accomplishment in foreign subsidiaries and organizations have to be ready for it. Delineating what is salient for expatriate mission accomplishment and what is not, helps organizations to ensure that the right people are expatriated. In the context of emerging economies, this study suggested that factors such as cultural competence, positivity, socialization skills, professional skills and work related matters are crucial for expatriate mission accomplishment. While Asian cultures are similar in many ways, differences do exist that can affect the performance of both expatriates and local staff. As organizational inclusion fosters expatriate work adjustment, organizations benefit from greater inclusivity in expatriation. Assignment types have changed and so has the demographic profiles of expatriates. Therefore, attention should be given to having a more diverse workforce to manage subsidiaries abroad. 
This study offers important theoretical and practical contributions to the literature. Theoretically, this study contributes expatriation literature on the importance of organizational inclusion in expatriate mission accomplishment in the Chinese context, particularly in emerging economies. Studies have mainly focused on the enablers of expatriate success or adjustment (e.g., Cheng and Lin, 2009; Davies et al., 2019; Harari et al., 2018; Lauring et al., 2019; van de Laken et al., 2019), but so far, none has examined organizational inclusion. Practically, drawing on Nicholson's (1984) work role transition theory and Nijs et al. (2014) ability-affective talent framework, this study enlightens practitioners that appropriate talent identification measures heighten the likelihood of expatriates employing deliberate practices to enhance personal and role development to adjust in work contexts. It suggests that organizational inclusion in tandem with the ability and affective components of talents will promote the identification of culturally fit expatriates that enhance mission accomplishment abroad.

As expatriation is trending towards multicultural global teams, expatriates not only have to assimilate with host country nationals, but also, expatriates of different nationalities. This goes beyond cultural competence - expatriates preferably must be agile, have a positive and open mindset as well as the ability to socialize well. While young talents may lack experience, preparing them adequately for expatriation may benefit organizations as they may adapt better in the foreign environment. Moreover, it is a measure to mitigate the possibility of brain drain to more developed economies. Therefore, organizational awareness and emphasis on organizational inclusion is imperative to retain talents. The current study provides an insight of the existing expatriation policies of an Asian emerging economy of Chinese context and provides justification for more organizational inclusion in expatriation to foster mission accomplishment. These insights would be helpful for policy makers of emerging economies to decide whether to consider organizational inclusion when designing development programs and career trajectory to create a pool of human resources that can be utilized globally.

With more women entering the workforce in emerging economies, the rising role of women in contributing to the bottom line deserves attention. Therefore, selection criteria for expatriation need to be more inclusive so that even young women may be given opportunities for expatriation. Traditionally, in line with Asian culture, there is always the tendency that senior males are favoured for expatriation. However, factors such as cultural competence, positivity, socialization skills, professional skills and work-related matters all affect expatriate mission accomplishment. Thus, embracing organizational inclusion in expatriate selection plausibly assists in the identification of employees, regardless of gender and seniority. As long as they are capable of coping or countering challenges (Davies et al., 2019) and adapt to new, distressing, or even traumatic situations (Hobfoll, 2002), they ought to be given due consideration. The capability of their expatriates to counter challenges arising from relocation to a new environment and fit in swiftly is undeniably salient for expatriate mission accomplishment.

Finally, disruptive technologies have propelled digital natives to the forefront. Hence, they are a force to be reckoned and cannot be ignored. Although they are generally the younger staff, their agility, energy and digital savviness are traits that organizations ought to leverage to enhance expatriate mission accomplishment rate. Generally, more 
adventurous and exposed to the happenings around the globe through social media, the likelihood of digital natives to adapt to a new foreign environment is conceivably higher. Therefore, championing organizational inclusion in expatriation policies indefinitely enhances expatriate mission accomplishment. Indeed, organizational inclusion in expatriation is critical, given the lack of attention in Asian emerging economies. Moreover, the insights in this study are also informative to future expatriates, providing a narrative on how one can prepare for meaningful international assignments.

\section{References}

Ainscow, M., Booth, T., \& Dyson, A., (2006), Improving schools, developing inclusion, Routledge, London.

Bansal, P., \& Corley, K., (2011), "The coming of age for qualitative research: Embracing the diversity of qualitative methods", Academy of Management Journal, vol. 54, no. 2, pp. 233-237.

Baruch, Y., Altman, Y., \& Tung, R. L., (2016), "Career mobility in a global era: Advances in managing expatriation and repatriation", Academy of Management Annals, vol. 10, no. 1, pp. 841-889.

BGRS, (2019), "What's trending in global mobility in 2019?", Retrieved from: https://www.bgrs.com/insights-articles/whats-trending-in-global-mobility-in-2019/

Bhaskar-Shrinivas, P., Harrison, D. A., Shaffer, M. A., \& Luk, D. M., (2005), "Input-based and time-based models of international adjustment: Meta-analytic evidence and theoretical extensions", Academy of Management Journal, vol. 48, no. 2, pp. 257-281.

Brimhall, K. C., (2019), "Inclusion is important... But how do I include? Examining the effects of leader engagement on inclusion, innovation, job satisfaction, and perceived quality of care in a diverse non-profit health care organization", Non-profit and Voluntary Sector Quarterly, vol. 48, no. 4, pp. 716-737.

Brinkmann, S., \& Kvale, S., (2015), Interviews: Learning the craft of qualitative research interviewing, Sage Publication, London.

Bucker, J., Poutsma, E., Schouteten, R., \& Nies, C., (2020), "The development of HR support for alternative international assignments: From liminal position to institutional support for short-term assignments, international business travel and virtual assignments", Journal of Global Mobility, vol. 8, no. 2, pp. 249-270.

Buttner, H. E., Lowe, K. B., \& Billings-Harris, L., (2012), "An empirical test of diversity climate dimensionality and relative effects on employee of colour outcomes", Journal of Business Ethics, vol. 110, no. 3, pp. 247-258.

Caligiuri, P. M., (2000), "The big five personality characteristics as predictors of expatriate success", Personnel Psychology, vol. 53, no. 1, pp. 67-88.

Caligiuri, P. M., \& Bonache, J., (2016), "Evolving and enduring challenges in global mobility", Journal of World Business, vol. 51, no. 1, pp. 127-141.

Caligiuri, P. M., Phillips, J., Lazarova, M., Tarique, I., \& Burgi, P., (2001), "The theory of met expectations applied to expatriate adjustment: The role of cross-cultural training", International Journal of Human Resource Management, vol. 12, no. 3, pp. 357-372.

Chen, C., (2019), "Disability and employment in Taiwan", Retrieved from: http://www.winklerpartners.com/?p=9541

Cheng, H. L., \& Lin, C. Y. Y., (2009), "Do as the large enterprises do? Expatriate selection and overseas performance in emerging markets: The case of Taiwan SMEs", International Business Review, vol. 18, no. 1, pp. 60-75. 
Cho, S., \& Mor Barak, M. E., (2008), "Understanding of diversity and inclusion in a perceived homogeneous culture: A study of organizational commitment and job performance among Korean employees", Administration in Social Work, vol. 32, no. 4, pp. 100-126.

Collings, D. G., (2014), "Integrating global mobility and global talent management: Exploring the challenges and strategic opportunities", Journal of World Business, vol. 49, no. 2, pp. 253-261.

Crown World Mobility, (2019), "World mobility perspectives: Big global mobility trends to watch in 2019", Retrieved from: https://www.crownworldmobility.com/wpcontent/uploads/2019/02/Big-global-mobility-trends-to-watch-in-2019-CWM.pdf

Davies, S. E., Stoermer, S., \& Froese, F. J., (2019), "When the going gets tough: The influence of expatriate resilience and perceived organizational inclusion climate on work adjustment and turnover intentions", International Journal of Human Resource Management, vol. 30, no. 8, pp. 1393-1417.

Deloitte, (2019), "Global workforce insight 2019: Assessing the predicted 2018 global mobility trends and their continued impact in 2019", Retrieved from: https://www2.deloitte.com/content/dam/Deloitte/ch/Documents/tax/deloitte-ch-Backto-the-future-global-workforce.pdf

Dowling, P. J., \& Welch, D. E., (2005), International human resource management: Managing people in an international context, Thomson, Mason.

FIDI (2016), "2016 trends: The growing strategic importance of global mobility", Retrieved from: https://www.fidi.org/blog/2016-global-mobility-trends

Gioia, D. A., Corley, K. G., \& Hamilton, A. L., (2012), "Seeking qualitative rigor in inductive research: Notes on the Gioia methodology", Organizational Research Methods, vol. 16, no. 1 , pp. 15-31.

Global Diversity Practice, (2017), "What is diversity \& inclusion?", Retrieved from: http://www.globaldiversitypractice.co.uk/what-is-diversity-inclusion/

Guba, E. G., \& Lincoln, Y. S., (1989), Fourth generation evaluation, Sage Publications, Newbury Park, California.

Half, R., (2018), "Gen Z characteristics employers need to understand", Retrieved from: https://www.roberthalf.com/blog/management-tips/gen-Z-characteristics-employersneed-to-understand

Hammersley, M., \& Atkinson, P., (1997), Ethnography: Principles in practice, Routledge, London.

Harari, M. B., Reaves, A. C., Beane, D. A., Laginess, A. J., \& Viswesvaran, C., (2018), "Personality and expatriate adjustment: A meta-analysis", Journal of Occupational and Organizational Psychology, vol. 91, no. 3, pp. 486-517.

Hobfoll, S. E., (2002), "Social and psychological resources and adaptation", Review of General Psychology, vol. 6, no. 4, pp. 307-324.

Hooi, L. W., (2019), "Global human resources: A key to mission accomplishment", Journal of Global Mobility, vol. 7, no. 1, pp. 5-26.

Hsiao, F. S. T., \& Hsiao, M., (n.d.), "Taiwan in the global economy - Past, present, and future", Retrieved from: www.colorado.edu/Economics/mcguire/workingpapers/Taiw anGlobalEconomy.pdf

Hu, H. H., Chen, Y. T., \& Chen, H. Y., (2010), "A study of Taiwanese executives selected for expatriate assignments", Contemporary Management Research, vol. 6, no. 3, pp. 201220.

Hwang, J., \& Hopkins, K., (2012), "Organizational inclusion, commitment, and turnover among child welfare workers: A multilevel mediation analysis", Administration in Social Work, vol. 36, no. 1, pp. 23-39.

Jang, Y., Wang, Y. T., \& Lin, M. H., (2014), "Factors affecting employment outcomes for people with disabilities who received disability employment services in Taiwan", Journal of Occupational Rehabilitation, vol. 24, no. 1, pp. 11-21. 
Ko, H. C., (2008), "Study of the success of Taiwanese expatriate managers on overseas assignments: A grounded theory approach", Theses \& Dissertations, Retrieved from: http://athenaeum.uiw.edu/uiw_etds/203

KPMG, (2019), "2019 Global assignment policies and practices survey" Retrieved from https://home.kpmg/xx/en/home/insights/2016/10/global-assignment-policies-andpractices-survey-2016.html

Lauring, J., Selmer, J., \& Kubovcikova, A., (2019), "Personality in context: Effective traits for expatriate managers at different levels", International Journal of Human Resource Management, vol. 30, no. 6, pp. 1010-1035.

Levy, O., Beechler, S. Taylor, S., \& Boyacigiller, N. A., (2007), "What we talk about when we talk about 'global mindset': Managerial cognition in multinational corporations", Journal of International Business Studies, vol. 38, no. 2, pp. 231-258.

Liggans, G., Attoh, P. A., Gong, T., Chase, T., Russell, M. B., \& Clark, P. W., (2019), "Military veterans in federal agencies: Organizational inclusion, human resource practices, and trust in leadership as predictors of organizational commitment", Public Personnel Management, vol. 48, no. 3, pp. 413-437.

Liisa M., Saarenpää, K., \& McNulty, Y., (2017), "Flexpatriates, short-term assignees and international commuters", In Yvonne McNulty and Jan Selmer (eds.), Research Handbook of Expatriates, Edward Elgar, Cheltenham.

Mendenhall, M., \& Oddou, G., (1985), "The dimensions of expatriate acculturation: A review", Academy of Management Review, vol. 10, no. 1, pp. 39-47.

Mitchell, R., Boyle, B., Parker, V., Giles, M., Chiang, V., \& Joyce, P., (2015), "Managing inclusiveness and diversity in teams: How leader inclusiveness affects performance through status and team identity", Human Resource Management, vol. 54, no. 2, pp. 217-239.

Mockaitisa, A. I., Zanderb, L., \& Cieria, H. D. (2018), "The benefits of global teams for international organizations: HR implications", International Journal of Human Resource Management, vol. 29, no. 14, pp. 2137-2158.

Mohamed, M., \& Vesa, P., (2019), "Inspiring organizational commitment: Responsible leadership and organizational inclusion in the Egyptian health care sector", Journal of Management Development, vol. 38, no. 3, pp. 208-224.

Nicholson, N., (1984), “A theory of work role transitions", Administrative Science Quarterly, vol. 29, no. 2, pp.172-191.

Nijs, S., Gallardo-Gallardo, E., Dries, N., \& Sels, L., (2014), "A multidisciplinary review into the definition, operationalization, and measurement of talent", Journal of World Business, vol. 49, no. 2, pp. 180-191.

O'Neil, D. A., \& Bilimoria, D., (2005). "Women's career development phases: Idealism, endurance, and reinvention", Career Development International, vol. 10, no. 3, pp. 168-189.

Ott, D. L., \& Michailova, S., (2016), "Expatriate selection: A historical overview and criteria for decision-making", International Business \& Management, vol. 32, pp. 1-24.

Patel, D., (2017), "8 ways Generation Z will differ from Millennials in the workplace", Retrieved from: https://www.forbes.com/sites/deeppatel/2017/09/21/8-waysgeneration-z-will-differ-from-millennials-in-the-workplace/\#7ff1008d76e5

Patton, M., (2015), Qualitative research and evaluation methods: Integrating theory and practice, Sage Publication, London.

Pelled, L. H., (1996), "Demographic diversity, conflict, and work group outcomes: An intervening process theory", Organization Science, vol. 7, no. 6, pp. 615-631.

Pichler, S., Varma, A., \& Budhwar, P., (2012), "Antecedents and consequences of the social categorization of expatriates in India", International Journal of Human Resource Management, vol. 23, no. 5, pp. 915-927.

Qi, L., Liu, B., Wei X., Hu, Y., (2019), "Impact of inclusive leadership on employee innovative behavior: Perceived organizational support as a mediator", PLOS ONE, vol. 14, no. 2, pp. 1-14. 
Renn, R., Allen, D., \& Huning, T., (2013), "The relationship of social exclusion at work with self-defeating behaviour and turnover", Journal of Social Psychology, vol. 153, no. 2, pp. 229-249.

Searle, W., \& Ward, C., (1990), "The prediction of psychological and sociocultural adjustment during cross-cultural transitions", International Journal of Intercultural Relations, vol. 14, no. 4, pp. 449-464.

Selmer, J., Lauring, J., Normann, J., \& Kubovcikova, A., (2015), "Context matters: Acculturation and work-related outcomes of self-initiated expatriates employed by foreign vs. local organizations", International Journal of Intercultural Relations, vol. 49, no. 11 , pp. 251-264.

Shah, D., \& Barker, M., (2017), "Cracking the cultural code: Indian IT expatriates' intercultural communication challenges in Australia", International Journal of CrossCultural Management, vol. 17, no. 2, pp. 215-236.

Sharma. S., \& Dahiya, R., (2017), "Expatriates cross-cultural adjustment challenge in diverse India: A three level analysis", International Journal of Indian Culture and Business Management, vol. 14, no. 3, pp. 347-364.

Shepherd, D., \& Sutcliffe, K., (2011), "Inductive top-down theorizing: A source of new theories of organization", Academy of Management Review, vol. 36, no. 2, pp. 361-380.

Shiraki, M. (2015), "Why 'global human resources' are urgently needed in Japan", Japan's HRM \& IR Information - Special article, Retrieved from: www.aots.jp/en/proje ct/eocp/summary.html

Silverman, D., (2018), Doing qualitative research, Sage Publication, London.

Smith, P. B., \& Bond, M. H., (1993), Social psychology across cultures: Analysis and perspectives, Allyn and Bacon, Boston.

Starman, A. B., (2013), "The case study as a type of qualitative research", Journal of Contemporary Educational Studies, vol. 64, no. 1, pp. 28-43.

Taiwan News, (2019), "Taiwan economy tops Four Asian Tigers despite lowered forecast", Retrieved from: https://www.taiwannews.com.tw/en/news/3764024

Talent Intelligence, (2014), "Inclusion and the benefits of diversity in the workplace", Retrieved from: http://www.talentintelligence.com/blog/bid/377611/inclusion-and-thebenefits-of-diversity-in-the-workplace

Tharenou, P., (2013), "Self-initiated expatriates: An alternative to company-assigned expatriates?", Journal of Global Mobility, vol. 1, no. 3, pp. 336-356.

Thompson, S., (2017), "Defining and measuring 'inclusion' within an organisation", Retrieved from: https://assets.publishing.service.gov.uk/media/5bace6fb40f0b62dd732 c49f/123_-_Defining_and_measuring_inclusion_within_an_organisati.pdf

Tung, R. L., (1987), "Expatriate assignments: Enhancing success and minimizing failures", Academy of Management Executive, vol. 1, no. 2, pp. 117-126.

Tung, R. L., (2016), "New perspectives on human resource management in a global context", Journal of World Business, vol. 51, pp. 142-152.

Vakalahi, H., (2012), "Cultural context of health and well-being among Samoan and Tongan American elders", Indian Journal of Gerontology, vol. 26, no. 1, pp. 75-93.

van der Laken, P. A., van Engen, M. L., van Veldhoven, M. J. P. M., \& Paauwe, J., (2016), "Expatriate support and success: A systematic review of organization-based sources of social support", Journal of Global Mobility, vol. 4, no. 4, pp. 408-431.

van der Laken, P. A., van Engen, M. L., van Veldhoven, M. J. P. M., \& Paauwe, J., (2019), "Fostering expatriate success: A meta-analysis of the differential benefits of social support", Human Resource Management Review, vol. 29, no. 4, pp. 1-20.

Van Manaan, J., (1979), "The fact of fiction in organizational ethnography", Administrative Science Quarterly, vol. 24, pp. 539-550.

Varma, A., Pichler, S., Budhwar, P., \& Kupferer, S., (2012), "Expatriate-local interactions: An investigation in China", Journal of Managerial Psychology, vol. 27, no. 7, pp. 753768. 
Wallace, W., \& Pillans, G., (2016), "Creating an inclusive culture", Retrieved from: http://www.crforum.co.uk/wp-content/uploads/2016/11/11-Creating-an-InclusiveCulture-1.pdf

Weick, K., (1995), Sensemaking in organizations, Sage Publication, London.

Welch, C., \& Piekkari, R., (2017), "How should we (not) judge the 'quality' of qualitative research? A reassessment of current evaluative criteria in International Business", Journal of World Business, vol. 52, no. 5, pp. 714-725.

Zhong, Y., (2016), "Explaining national identity shift in Taiwan", Journal of Contemporary China, vol. 25, no. 99, pp. 336-352. 